\title{
Research on the Factors Affecting Division of Labor in Manufacturing in the Middle Reaches of the Yangtze River
}

\author{
Chunjiao Liu \\ Wu Han University of Technology, Wu Han, China
}

\begin{abstract}
Keywords: Urban agglomerations in the middle reaches of the Yangtze River; Division of Labor in manufacturing; Affecting factors
\end{abstract}

\begin{abstract}
Deepening the rational division of labor among the manufacturing industries in the middle reaches of the Yangtze River has far-reaching significance for implementing the regional coordinated development strategy proposed by the 19th CPC national congress. Based on the data from 2005 to 2016 , this paper makes an empirical analysis of factors of production, economic status, external relations and green development affecting the division of labor in the manufacturing industry by building a model, and puts forward policy suggestions on optimizing the division of labor in the urban cluster of the middle reaches of the Yangtze river from the strategic level, industrial structure and opening to the outside world.
\end{abstract}

\section{Introduction}

In order to participate in the global value chain division, China attaches great importance to the development of the manufacturing industry, and has launched some policy documents such as made in China 2025, among which the reasonable division of industrial distribution is one of the core issues to promote the sustainable and healthy development of the industry. At present, the industrial division of urban agglomerations in the middle reaches of the Yangtze River is faced with profound problems, which are as follows: first, the main body's hard environment is not perfect, and the soft environment is not connected. Second, urban agglomerations are not concentrated, and the economic benefits brought by the division of labor cannot be formed. Third, the diversification of interest subjects and all subjects pursue their own interest maximization, resulting in the failure to obtain the division of labor benefits. Therefore, an in-depth study of the factors influencing the division of labor in the middle reaches of the Yangtze River has important practical significance.

\section{Literature Review}

At present, there are many researches on the factors affecting industrial division of labor at home and abroad, mainly focusing on the division of labor calculation, division of labor characteristics and influencing factors. Among them, Krugman (1991) proposed that regional aggregation caused by economies of scale can reduce production costs and increase competitiveness, and transportation factors can form a larger market ${ }^{[1]}$. Rex (1995) used the locational quotient index to analyze the regional distribution of American manufacturing ${ }^{[2]}$. Ellis (2007) studied the industrial division of labor or coordination in the world through the correlation of labor force and industry ${ }^{[3]}$. In China, Li Na (2008) constructed the mechanism framework of industrial division of labor from production factors, region itself and environmental factors ${ }^{[4]}$. Wang Yuyan (2018) made an empirical study on the industrial division of the Yangtze River economic belt from aspects of production factors, natural resources, spatial connection and institutional factors ${ }^{[5]}$. This paper mainly takes the urban agglomerations in the middle reaches of the Yangtze River as the object, introduces the green development index, and more comprehensively explores the factors influencing its industrial division of labor.

\section{Empirical Analysis}

\subsection{Model building}

Regional division of labor index is taken as the explained variable. In existing literature, factors of production and economic status are often taken as important factors. This paper holds that external 
relations and green development also play an important role in industrial division of labor. Therefore, the following log-base model is constructed:

$$
L N R I D I_{t}=\alpha+\beta_{1} L N F P_{t}+\beta_{2} L N S E_{t}+\beta_{1} L N O C_{t}+\beta_{1} L N G D_{t}+\varepsilon_{t}
$$

(1) Industrial division of labor $\left(R I D I_{t}\right)$. the division of regional industry in the t period of province $i$ is:

$$
R I D I_{i, t}=\frac{\sum_{j=1, j \neq i}^{N-1} I D I_{i j, t}}{N-1}
$$

$R I D I_{i, t}$ is the regional industrial division index of the $\mathrm{t}$ period of $\mathrm{i}$ province, $I D I_{i j, t}$ is the regional industrial division index between i province and $\mathrm{j}$ province in the period $\mathrm{t}$. Its calculation formula is as follows is:

$$
I D I_{i j, t}=\sum_{k=1}^{k}\left|\frac{Y_{i k, t}}{Y_{i, t}}-\frac{Y_{j k, t}}{Y_{i, t}}\right|
$$

Among them, i, j represents the province, k represents the number of industrial sectors, and $Y_{j k, t}$ represent the output value of the $\mathrm{k}$ industry in the $\mathrm{t}$ period of $\mathrm{i}$ and $\mathrm{j}$ provinces, $Y_{i, t}$ represent the total industrial output value in the $t$ period of $i$ and $j$ provinces. If the industrial structure of the two provinces is identical, the index value is 0 ; if it is unrelated, the index value is 2 .

(2) Production factors $\left(F P_{t}\right)$. Manufacturing employment as a proportion of total Numbers measures human capital $\left(H C_{t}\right)$, the proportion of added value of the tertiary industry to GDP measures the level of tertiary industry development $\left(P C_{t}\right)$, and the research funds of the industrial sector account for the proportion of the total value of industrial sales $\left(T C_{t}\right)$.The data come from China statistical yearbook and China science and technology statistical yearbook.

(3) Economic situation ( $\left.S E_{t}\right)$. The per capita GDP is used to measure the level of economic development ( $\left.L E_{t}\right)$, and the added value of the tertiary industry as a percentage of GDP is measured by the level of development of the tertiary industry $\left(T L E_{t}\right)$. Data come from China statistical yearbook.

(4) External contacts $\left(O C_{t}\right)$. The road network density of water, road and railway indicates the degree of traffic contact $\left(D T C_{t}\right)$, and the degree of foreign trade $\left(D F T_{t}\right)$ is calculated as follows:

$$
D F T_{\mathrm{t}}=\left|\frac{\frac{S_{0}}{G D P_{0}}}{G} / \frac{S_{\mathrm{i}}}{G D P_{\mathrm{i}}}\right|
$$

$S_{0}$ is the final consumption of the national gross domestic product calculated by the expenditure method. $G D P_{0}$ is the national gross domestic product. $S_{\mathrm{i}}$ is the gross domestic product of the i region calculated by the expenditure method. $G D P_{\mathrm{i}}$ is the region's gross domestic product. Data come from China statistical yearbook.

(5) Green development $\left(G D_{t}\right)$. Energy consumption rate of industrial energy consumption above designated size as a percentage of industrial added value $\left(E E R_{i t}\right)$, The proportion of total industrial waste discharge to industrial growth is measured as the proportion of effluent discharge per unit of industrial value added $\left(A D R_{i t}\right)$. Data come from China statistical yearbook.

Therefore, the final model is built as follows:

$$
\begin{aligned}
& \text { LNRIDI }_{t}=\alpha+\beta_{11} L_{N H C}+\beta_{12} L_{N P C_{t}}+\beta_{13} L N T C_{t}+\beta_{21} L N L E_{t}+\beta_{22} T L E_{i t}+ \\
& \beta_{31} L N D F T_{t}+\beta_{32} L N D T C_{t}+\beta_{41} L N E E R_{t}+\beta_{42} L N A D R_{t}+\varepsilon_{t}
\end{aligned}
$$




\subsection{Measurement results and analysis}

\subsubsection{Unit root test}

Before performing a cointegration analysis, you must first check if the variables are stationary. The stability test of the variables and their first-order difference variables was carried out using Dickey-Fuller's ADF test method. The results are shown in Table1

Table1 ADF unit root test for variables

\begin{tabular}{|c|c|c|c|c|}
\hline Variables & ADF test & Inspection type (c, t, k) & Threshold & Conclusions \\
\hline LNRIDI & 1.518357 & $(c, 0,4)$ & -1.600140 & Non-stable \\
\hline LNHC & -0.222024 & $(c, 0,4)$ & -1.602074 & Non-stable \\
\hline LNPC & 0.899517 & (c, 0,4$)$ & -1.601144 & Non-stable \\
\hline LNTC & -0.010780 & (c, 0,4$)$ & -1.601144 & Non-stable \\
\hline LNLE & 1.115256 & (c, 0,4$)$ & -1.601144 & Non-stable \\
\hline LNTLE & -0.957592 & (c, 0,4$)$ & -1.602074 & Non-stable \\
\hline LNDFT & 0.258524 & $(c, 0,4)$ & -1.601144 & Non-stable \\
\hline LNDTC & 1.370846 & $(c, 0,4)$ & -1.602074 & Non-stable \\
\hline LNEER & -0.924984 & $(c, 0,4)$ & -1.602074 & Non-stable \\
\hline LNADR & -0.112344 & $(c, 0,4)$ & -0.623456 & Non-stable \\
\hline D(LNRIDI) & -4.440847 & $(c, 0,4)$ & $-4.440847 * * *$ & stable \\
\hline $\mathrm{D}(\mathrm{LNHC})$ & -4.420662 & $(c, 0,4)$ & $-3.515047 *$ & stable \\
\hline $\mathrm{D}(\mathrm{LNPC})$ & -3.590496 & $(c, 0,4)$ & $-20.32401^{* * *}$ & stable \\
\hline D(LNTC) & -4.918908 & $(c, 0,4)$ & $-2.801384 * * *$ & stable \\
\hline D(LNLE) & -3.865802 & $(c, 0,4)$ & $-3.590496 *$ & stable \\
\hline D(LNTLE) & -2.824127 & $(c, 0,4)$ & $-2.747676 *$ & stable \\
\hline D(LNDFT) & -4.538844 & $(c, 0,4)$ & $-2.747676^{* * *}$ & stable \\
\hline D(LNDTC) & -26.95673 & $(c, 0,4)$ & $-2.747676^{* * *}$ & stable \\
\hline D(LNEER) & -2.223488 & $(c, 0,4)$ & $-2.223456 *$ & stable \\
\hline D(LNADR) & -3.312 & $0,4)$ & 2344 & stable \\
\hline
\end{tabular}

Note: The test type (c, t, k) indicates whether there is a constant term c, a time trend term t, and a lag period of $\mathrm{k}$ in the ADF test; ***, **, * respectively indicate that the value is $1 \%, 5 \%, 10 \%$ of the critical value at the significant level; D (LNHC) and others represents the first order difference of the variable.

It can be seen from table 1 that the test values of all variables are greater than the critical value of $10 \%$ of their significance level through the ADF test, indicating that these sequences have unit roots and are non-stationary. At the same time, the first-order difference of all variables is stable, so there may be a co-integration relationship in the sequence.

\subsubsection{Cointegration test}

Using the E-G two-step method, the cointegration relationship between the independent variable and the dependent variable is tested. The test results are as follows:

The first step is to estimate the equation. First, the co-integration vector is estimated by the OLS method, and then the residual root has a unit root. Use Eviews9.0 to get the following equation:

$$
\begin{aligned}
& \text { LNRIDI }_{t}=-0.077142-0.768324 \mathrm{LNHC}_{t}-0.293691 \mathrm{LNPC}_{t}-0.486688 \mathrm{LNTC}_{t}+0.089918 \mathrm{LNLE}_{t} \quad \text { The second step } \\
& -0.038254 \mathrm{LNTLE}_{t}+0.412633 \mathrm{LNDFT} T_{t}+0.027067 \mathrm{LNDTC} C_{t}-0.061324 \mathrm{LNEER}_{t}-0.037067 \mathrm{LNADR}_{t}
\end{aligned}
$$

is to test the unit root of the residual. Therefore, the estimated residual sequence rejects the null hypothesis at the $5 \%$ level, that is, accepts the conclusion that there is no unit root (shown as Table 2). Therefore, it can be determined that the estimated residual is zero-order monotonic, and the above results indicate that there is a long-term stable relationship between the explanatory variable and the interpreted variable.

Table 2 Unit root test for residuals

\begin{tabular}{ccccc}
\hline Variable & ADF test & Inspection type (c, t, k) & Threshold & Conclusion \\
\hline RIDI & -2.623456 & (c, 0,4$)$ & $-2.483433^{* *}$ & Stable \\
\hline $\begin{array}{l}\text { Note: the type of test (c,t,k) respectively indicates whether there will be constant term c, time trend term t and lag period in ADF test. } \\
\text { and } * \text { indicate the critical value under the significance level of }\end{array}$ \\
represent variables.
\end{tabular}




\subsubsection{Results analysis}

The empirical test results show that, firstly, human capital, material capital and technical capital are negatively correlated, which is significant at the level of $5 \%$, indicating that factors of production are the main determinant of poor industrial division of labor. The input of production factors promotes the economic development, but the relatively concentrated input of production factors into the same industry leads to obvious industrial convergence in different provinces. Second, the level of economic development and the development of tertiary industry are positively correlated, and the level of $10 \%$ is significant. The economic development requires rational and refined division of labor in the manufacturing industry, while the development of the tertiary industry can deepen the division of labor. Third, the degree of foreign trade presented a positive correlation, and was significant at the $10 \%$ level, while the degree of traffic connection presented a positive correlation, but not significant. It shows that improving the accessibility of regional transportation network and improving the level of opening to the outside world are conducive to the rational division of labor in the manufacturing industry. Fourthly, the energy consumption is negative and significant at $10 \%$ level, while the percentage of sewage discharge increased by unit industry is negative but insignificant. This shows that the green development of urban agglomerations is insufficient, which to some extent inhibits the division of labor in the manufacturing industry.

\section{Summary}

The above results have the following policy implications:

Firstly, the inter-provincial coordination mechanism of industrial division among provinces and cities in the middle reaches of the Yangtze River was constructed from the strategic level. It is suggested that the government should adhere to the basic principles of deepening the specialization and inter-provincial cooperation, and establish the inter-provincial coordination mechanism of industrial division among the cities in the middle reaches of the Yangtze River.

Second, optimize industrial structure and provide strong impetus for the optimization of regional industrial division. Accelerate the development of strategic emerging industries, deepen the integration of industrialization and informatization, implement green manufacturing projects and develop high-tech services and science and technology services.

Third, create a new pattern of opening-up. Both east and west opening-up and land and sea opening-up should be carried out to build a new pattern of all-round opening in the new era. And we should adhere to market orientation, weaken administrative intervention.

\section{Acknowledgment}

The paper is supported by the Fundamental Research Funds for the Centre Universities.

\section{References}

[1] Krugman, P. Geography and Trade[M] .MI T Press, Cambridge M A,1991

[2] Rex T. Prominent Industry Clusters Vary by County [J]. Arizona Business, 1999, 46(6): 628.

[3] Ellis M. Geography and the Immigrant Division of Labor, Economic Geography, 2007, 83(3):255-281.

[4] Li Na. Analysis of industrial division of labor mechanism based on the new international and domestic background [J]. World geography research, 2008, 17(04):9-16. (In Chinese)

[5] Wang Yuyan, Wang Ling. Research on industrial division change and its influencing factors in the Yangtze River economic belt [J]. Business research, 2018(03):123-131. (In Chinese) 
[6] Shi Junwei, Wang Yuyan. Measurement and determination of industrial structure isomorphism in western provinces of China -- analysis and empirical test based on SIP framework [J]. China industrial economy, 2013(3):33-45(In Chinese) 